\title{
Synthesis and Characterization of Surface Ion-imprinted Polymer Based on Mesoporous Silica SBA-15 for Selective Removal of Cu(II) from Aqueous Solutions
}

\author{
Sheng-fang $\mathrm{LI}^{1}$, Lin YANG ${ }^{1}$, Wei-jun SONG ${ }^{1}$ and Chun-yan SUN ${ }^{1, *}$ \\ ${ }^{1}$ Department of Chemical Engineering, Qinghai University,Xining, China. \\ Corresponding Author*e-mail: sunchunyan@qhu.edu.cn \\ e-mail: 1620449624@qq.com
}

\begin{abstract}
A Cu(II) ion-imprinted polymer (Cu(II)-IIP) for the selective adsorption and separation of $\mathrm{Cu}$ (II) was prepared by modifying the surface of mesoporous silica SBA-15 through surface ion imprinting. The prepared polymer was characterized by Fourier transmission infrared spectra (FTIR), X-ray diffraction (XRD), Energy disperse spectrometer (EDS), Thermogravimetric analysis(TGA), Scanning electron microscope (SEM), Transmission electron microscope (TEM) and nitrogen adsorption-desorption isotherm. Batch adsorption tests were investigated on the effects of solution $\mathrm{pH}$ value, contact time and different initial $\mathrm{Cu}(\mathrm{II})$ ion concentrations. The results showed that the $\mathrm{Cu}$ (II)-IIP has higher adsorption capacity and selectivity than that of nonimprinted polymer (NIP). The adsorption isotherm followed Langmuir model. The kinetic data well fitted the pseudosecond-order kinetic model compared with the pseudo-firstorder kinetic model. The selectivity coefficients for $\mathrm{Cu}(\mathrm{II}) / \mathrm{Cd}(\mathrm{II}), \mathbf{C u}(\mathrm{II}) / \mathrm{Fe}(\mathrm{II}), \mathbf{C u}(\mathrm{II}) / \mathrm{Co}(\mathrm{II}), \mathrm{Cu}(\mathrm{II}) / \mathrm{Pb}(\mathrm{II})$ were 3.56, 2.32, 11.75, 4.73, respectively. In addition, Adsorption capacity did not significantly decrease after five adsorptiondesorption cycles were completed. demonstrating that the polymer is stable and reusable.
\end{abstract}

Keywords-Ion-imprinted polymer; Mesoporous silica ; Surface imprinting technology; Cu(II) ; Adsorption

\section{INTRODUCTION}

Copper is an essential trace element for our health, but excessive amount of copper in human body can cause serious damage, even it can be toxic at the concentrations as low as $1 \mu \mathrm{g} \cdot \mathrm{L}^{-1}[1,2]$. Nowadays water pollution by heavy metals has become a worldwide environmental problem because of their toxicity towards aquatic-life, human beings and environment [3-5]. Thus, effective removal and determination of trace amounts of copper in the environmental or biological samples is essential.

To date, numerous technologies have been developed for heavy metals removal from wastewater, such as electrodialysis, chemical precipitation, ion exchange, adsorption and membrane filtration [6-8]. Among them, adsorption plays an important role due to its flexibility in design, operation and superior efficiency under certain conditions [9]. Conventional absorbents, like activated carbon, zeolites, clays and metal oxides [10-13], have some disadvantages for the removal of heavy metals. Such as nonspecific, low selectivity, poor hydrothermal stability and low reusability [14]. On the other hand, various detection techniques has also been developed, including inductively coupled plasma optical emission spectrometry (ICP-OES), inductively coupled plasma mass spectrometry (ICP-MS) and atomic absorption spectrometry (AAS) $[15,16]$. AAS, nowadays is still one of the most frequently used analytical techniques for the metals determination. However, its relatively low sensitivity and performances in complex matrices seriously impact on its further applications in trace analysis [17]. Therefore, it is necessary to develop a highly selective sorbent for preconcentration and determination of $\mathrm{Cu}(\mathrm{II})$ ions in solutions.

Ion imprinting is a type of molecular imprinting technique with remarkable recognition properties because of their template ions [18]. Ion imprinting polymer (IIP) obtained by traditional methods may lead to the poor site accessibility to the target ions, slow mass-transfer rate and incomplete removal of templates, while a burgeoning method, surface imprinting $[19,20]$, to some extent, can solve the above problems.

The advances in this field have found that the support materials usually used include magnetic materials [21], carbon-based materials [22], silicon-based materials [23] and so on. Among mesoporous silicon family, SBA-15 is an attractive candidate to be used as a support for surface ion imprinting polymer due to its large surface area, highly ordered pore, thick pore walls with high hydrothermal stability and available surface functionalization [24,25]. Meng et al. [26] prepared cesium ion-imprinted polymer based on SBA-15 by RAFT polymerization strategies, the polymer exhibited more homogeneous and thin polymer layer with higher adsorption property than the polymer prepared using the free RAFT agent in solution . Liu et al. [27] Tailor-made ion-imprinted polymer based on functionalized graphene oxide for the preconcentration and determination of trace copper in food samples. which achieve the excellent combination of support materials and surface imprinting technique.

In the study, $\mathrm{Cu}$ (II)-IIP supported on SBA-15 was easily prepared with low cost via surface imprinting technique. The structural characteristics, adsorption behavior of the $\mathrm{Cu}$ (II)-IIP towards $\mathrm{Cu}$ (II) ions in aqueous solution were tested and discussed in detail. 


\section{EXPERIMENTAL}

\section{A. Materials and Chemicals}

Poly(ethyleneglycol)-block-poly(propyleneglycol)block-poly(ethylene glycol) $\left(\mathrm{EO}_{20} \mathrm{PO}_{70} \mathrm{EO}_{20}\right.$, molecular weight5800)(P123,Sigma,USA), tetraethylorthosilicate(TEO S),3-(methacryloxyl) propyltrimethoxysilane (MPS, 97\%), methyl acrylic acid (MAA, 98\%), ethylene glycoldimethacrylate (EGDMA, average $\mathrm{Mn}$ 750), 2,2'azobisisobutyronitrile (AIBN, 99\%) were purchased from Aladdin (Shanghai, China). All the other chemicals used were of analytical grade. Doubly distilled water (DDW) was used for all dilutions.

\section{B. Apparatus and Measurements}

Fourier-transform infrared (FT-IR) spectra were obtained with a Perkin-Elmer FTIR Spectrum BX-II spectrometer using $\mathrm{KBr}$ pellets over the range of 400-4000 $\mathrm{cm}^{-1}$ at room temperature. Energy dispersive spectrometry (EDS) was performed with a United Oxford Instruments JSM-5610LV/INCA using to confirm the existence of elements in $\mathrm{Cu}(\mathrm{II})$-IIP. The thermogravimetry (TG) analysis was performed with a NETZSCH STA 449 F3 instrument in owing $\mathrm{N}_{2}$ with a heating rate of $5{ }^{\circ} \mathrm{C} / \mathrm{min}$. Small-angle Xray diffraction (SAXRD) analysis was carried out using a PANalytic X'Pert PRO MPD diffractometer over the $2 \theta$ range of $0.5^{\circ}-5^{\circ}, \mathrm{CuKa}(40 \mathrm{kV}$ and $20 \mathrm{~mA})$ radiation was used. The step size was $0.008^{\circ}$ and the nominal collecting time was $50.16 \mathrm{~s}$ per step. Scanning electron microscopy (SEM) was utilized for assessing the morphology of the obtained polymers by using JEOL JSM-6610LV at $25 \mathrm{kV}$. Transmission electron microscopy (TEM) images were taken using a Tecnai TF20 G2 FEG-TEM at $200 \mathrm{kV}$ accelerating voltage with a standard single-tilt holder. The sample was dispersed into anhydrous alcohol with ultrasonic treatment for $20 \mathrm{~min}$, and the solution was deposited on a $\mathrm{Cu}$ grid. Nitrogen adsorption-desorption isotherms were obtained at $-197{ }^{\circ} \mathrm{C}$ using a $3 \mathrm{H}-2000 \mathrm{PS} 1$ specific surface area and pore size analyzer. Prior to the adsorption experiment, the materials were vacuum dried at $200{ }^{\circ} \mathrm{C}$ for $10 \mathrm{~h}$. The specific surface area and pore size distribution of the product were calculated by the BET and BJH methods, respectively. Flame atom absorption spectrometry (FAAS) was used to determination of $\mathrm{Cu}$ (II) ions and other metal ions such as $\mathrm{Cd}(\mathrm{II}), \mathrm{Fe}(\mathrm{II}), \mathrm{Co}(\mathrm{II})$, $\mathrm{Pb}$ (II) by using Shimadzu AA-6300C. All the solutions were prepared with ultra-pure water $(18.25 \mathrm{M} \Omega * \mathrm{~cm}$ resistivity) obtained from a Milli-Q Direct 16 water purification system.

\section{Preparation of $\mathrm{Cu}(\mathrm{II})-\mathrm{IIP}$}

\section{1) Preparation and activation of SBA-15}

SBA-15, as the support matrix, was synthesized according to Zhao et al. [28]. To obtain the activated SBA15 , the prepared SBA- 15 was treated with $3 \mathrm{~mol} \cdot \mathrm{L}^{-1} \mathrm{HCl}$ by refluxing for $24 \mathrm{~h}$ at $80{ }^{\circ} \mathrm{C}$, followed by washing with DDW to neutral $\mathrm{pH}$. Finally, the product was dried at $60{ }^{\circ} \mathrm{C}$. Then, the activated SBA-15 was obtained.
$150 \mathrm{mg}$ of activated SBA-15 and $3 \mathrm{~mL}$ MPS were dispersed in $40 \mathrm{~mL}$ absolute ethanol and stirred under nitrogen at $50{ }^{\circ} \mathrm{C}$ for $24 \mathrm{~h}$. The mixture was filtered and the modified SBA-15 (SBA-15@MPS) was rinsed with ethanol several times and dried at $60^{\circ} \mathrm{C}$ for $6 \mathrm{~h}$.

3) Preparation of $\mathrm{Cu}(\mathrm{II})-\mathrm{IIP}$

$1 \mathrm{mmol}$ of $\mathrm{CuCl}_{2}, 4 \mathrm{mmol}$ of MAA and $0.1 \mathrm{~g} \mathrm{SBA-}$ 15@MPS were dispersed into $30 \mathrm{~mL}$ of methanol and $10 \mathrm{~mL}$ DDW stirred under nitrogen at room temperature for $2 \mathrm{~h}$, after polymerization, $10 \mathrm{~mL}$ EGDMA and $10 \mathrm{mg}$ AIBN were added into this suspension. The resultant mixture was stirred by refluxing in a water bath at $65{ }^{\circ} \mathrm{C}$ for $6 \mathrm{~h}$ under nitrogen protection. Subsequently, the prepared polymer was washed with methanol/water $(4: 1, \mathrm{v} / \mathrm{v})$ for several times to purify the products. Finally, the adsorbent was treated with $2 \mathrm{~mol} \cdot \mathrm{L}^{-1} \mathrm{HCl}$ to completely leach the non-covalent $\mathrm{Cu}(\mathrm{II})$ and dried in vacuum. As a control, non-imprinted polymer was also prepared as a blank in parallel, but without the addition of $\mathrm{CuCl}_{2}$.

\section{Adsorption Experiments}

\section{1) Static adsorption studies}

Adsorption of $\mathrm{Cu}(\mathrm{II})$ from aqueous solutions was investigated in batch experiments. $20 \mathrm{mg}$ of $\mathrm{Cu}$ (II)-IIP was added into $20 \mathrm{~mL}$ of $\mathrm{Cu}$ (II) with different concentration in the $\mathrm{pH}$ range of 3-8 and the mixture was shaken for 180 min at $25{ }^{\circ} \mathrm{C}$. Afterwards, the mixture solution was centrifuged and the concentration of the residual $\mathrm{Cu}$ (II) was measured by FAAS. The absorption capacity $q_{e}, q_{t}\left(\mathrm{mg} \cdot \mathrm{g}^{-1}\right)$ at equilibrium and time $t(\mathrm{~min})$ were calculated as follows:

$$
\begin{gathered}
q_{e}=\frac{\left(C_{0}-C_{e}\right) V}{m} \\
q_{t}=\frac{\left(C_{0}-C_{t}\right) V}{m}
\end{gathered}
$$

where $C_{0}, C_{e}$ and $C_{t}\left(\mathrm{mg} \cdot \mathrm{L}^{-1}\right)$ are concentrations of $\mathrm{Cu}(\mathrm{II})$ at initial, equilibrium and time $t$ in aqueous phase, respectively. $V(\mathrm{~mL})$ and $m(\mathrm{~g})$ are the volume of solution and the mass of the sorbent, respectively.

2) Selectivity study

In order to measure the selectivity of the imprinted polymer, binary binding ability of $\mathrm{M}(\mathrm{Cd}(\mathrm{II}), \mathrm{Fe}(\mathrm{II}), \mathrm{Co}(\mathrm{II})$, $\mathrm{Pb}$ (II) )metals with respect to $\mathrm{Cu}$ (II) was investigated using $\mathrm{Cu}$ (II)-IIP and NIP. $20 \mathrm{mg}$ of $\mathrm{Cu}$ (II)-IIP or NIP was added in $20 \mathrm{~mL}$ of $100 \mathrm{mg} \cdot \mathrm{L}^{-1}$ binary metal mixed solutions. Finally, The distribution coefficient $K_{d}\left(\mathrm{~mL} \cdot \mathrm{g}^{-1}\right)$, selectivity coefficient $k$, and the relative selectivity coefficient $k^{\prime}$ [29] were given as follows:

$$
\begin{array}{r}
K_{d}=\frac{\left(C_{0}-C_{e}\right) V}{m C_{e}} \\
k=\frac{K_{d}(C u(\mathrm{II}))}{K_{d}(M)}
\end{array}
$$

\footnotetext{
2) Preparation of SBA-15@MPS
} 


$$
\mathrm{k}^{`}=\frac{\mathrm{k}_{I I P}}{k_{N I P}}
$$

where $K_{d}(C u(I I))$ and $K_{d}(M)$ represent the distribution coefficient of $\mathrm{Cu}(\mathrm{II})$ and $\mathrm{M}$ ions, respectively. $k_{I I P}$ and $k_{\mathrm{NIP}}$ represent the selectivity coefficient of $\mathrm{Cu}(\mathrm{II})$-IIP and NIP, respectively.

3) Reusability of the Cu(II)-IIP

To test the reusability of the $\mathrm{Cu}$ (II)-IIP, five cycles of adsorption-desorption were tested. The $\mathrm{Cu}$ (II) was removed from the sorbent by washing with $2 \mathrm{~mol} \cdot \mathrm{L}^{-1} \mathrm{HCl}$ and rinsed several times with DDW for neutralized $\mathrm{pH}$. Then, dried under vacuum at $60{ }^{\circ} \mathrm{C}$ for $6 \mathrm{~h}$ before another cycle.

\section{RESULTS AND DISCUSSION}

\section{A. Synthesis Strategy}

Fig. 1 illustrates the main steps of the strategy involved in surface imprinting procedure. The synthesis of $\mathrm{Cu}(\mathrm{II})-\mathrm{IIP}$ can be simply divided into three steps as follows: (1) vinyl groups were introduced to the surface of SBA-15 through chemical modification with MPS. (2) MAA immobilization on the decorated surface of SBA-15@MPS in the presence of $\mathrm{Cu}(\mathrm{II})$. In this step, surface imprinting was conducted and the shape memory polymer networks formed after the coordination between $\mathrm{Cu}(\mathrm{II})$ and the groups grafted on SBA-15. (3) removing chelated $\mathrm{Cu}(\mathrm{II})$ by $2 \mathrm{~mol} \cdot \mathrm{L}^{-1} \mathrm{HCl}$. The imprinted polymer which contained predetermined orientation and tailor-made cavities on surface of SBA-15 for $\mathrm{Cu}(\mathrm{II})$ was formed.

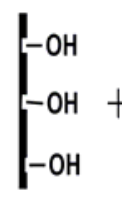

SBA-15<smiles>C=C(C)C(=O)OC[Si](OC)(OC)OC</smiles>

MPS<smiles>C=C(C)C(=O)OC[Si]12OCC(CC)(O1)O2</smiles>

SBA-15@MPS

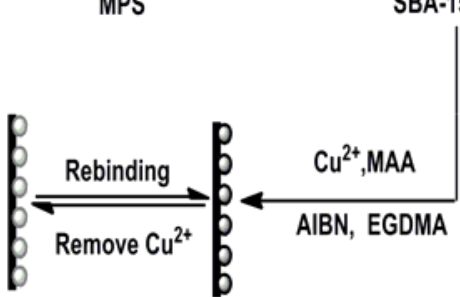

Fig. 1 Schematic illustration of preparation process of $\mathrm{Cu}(\mathrm{II})-\mathrm{IIP}$

\section{B. Characterization}

\section{1) FT-IR analysis}

Fig. 2 show the FT-IR spectra of SBA-15, SBA$15 @$ MPS and $\mathrm{Cu}(\mathrm{II})-\mathrm{IIP}$. All of the samples displayed the stretching and bending vibration of $\mathrm{Si}-\mathrm{O}-\mathrm{Si}$ bond around $1084 \mathrm{~cm}^{-1}, 803 \mathrm{~cm}^{-1}$ and $462 \mathrm{~cm}^{-1}$, suggesting that the structure of SBA-15 was well preserved after modification and polymerization. The peaks near $1635 \mathrm{~cm}^{-1}$ were attributed to stretching vibration of the surface Si-OH groups of SBA-15. The observed features around $3446 \mathrm{~cm}^{-1}$ indicate the stretching vibrations of $-\mathrm{OH}$. After grafting of the vinyl groups, SBA-15@MPS exhibited the characteristic peaks of $\mathrm{C}=\mathrm{O}$ bands at $1700 \mathrm{~cm}^{-1}$. In addition, the vibration absorption bands of $\mathrm{C}-\mathrm{H}$ bond near $2851 \mathrm{~cm}^{-1}, 2978 \mathrm{~cm}^{-1}$ also appeared. The results indicated that MPS was successfully introduced onto SBA-15. The $\mathrm{Cu}$ (II)-IIP exhibited obvious absorption bands around $1716 \mathrm{~cm}^{-1}$, which was due to the $\mathrm{C}=\mathrm{O}$ stretching vibration of carboxyl. All of the above results confirmed that $\mathrm{Cu}(\mathrm{II})$-IIP was successfully synthesized.

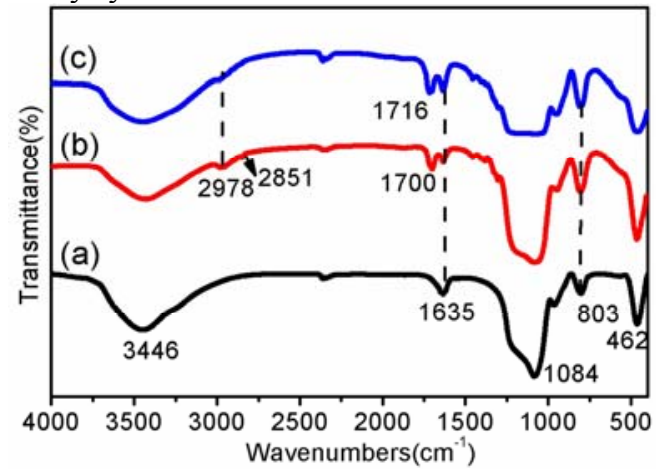

Fig. 2 FT-IR spectra of SBA-15(a), SBA-15-MPS(b), Cu(II)-IIP(c)

\section{2) EDS analysis}

The existence of $\mathrm{Cu}$ was further confirmed by the EDS analysis. In Fig. 3, the signal of oxygen and silica were the component of the SBA-15. The existence signal of carbon, which was due to the modification of MPS onto the surface of SBA-15. In addition, the signal of $\mathrm{Cu}$ was observed clearly in the sample of unleached $\mathrm{Cu}$ (II)-IIP (Fig. 3 a), and disappear after leached (Fig. $3 \mathrm{~b}$ ). The above results support that $\mathrm{Cu}(\mathrm{II})$ ion has been successfully incorporated into the polymer, and it can be removed simply by washing with $\mathrm{HCl}$ aqueous solution.

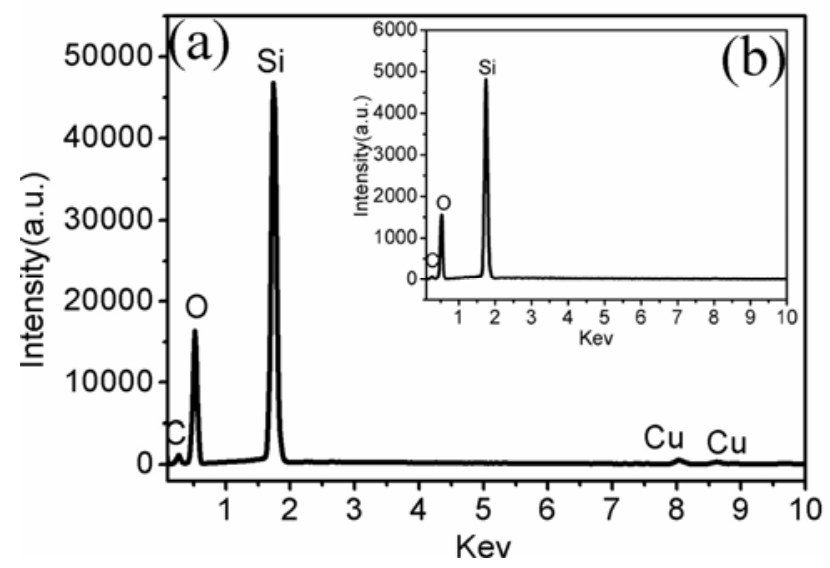

Fig. 3 EDS spectra of unleached $\mathrm{Cu}(\mathrm{II})-\mathrm{IIP}(\mathrm{a})$ and leached $\mathrm{Cu}(\mathrm{II})-\mathrm{IIP}(\mathrm{b})$

\section{3) XRD analysis}

Powder XRD patterns results were showed in Fig. 4. Three XRD peaks at $0.85^{\circ}, 1.50^{\circ}$ and $1.72^{\circ}$ were observed for $\mathrm{Cu}(\mathrm{II})-\mathrm{IIP}$, which corresponded to the (100), (110) and (200) reflections of SBA-15, respectively, suggesting that the structure of SBA-15 was well preserved. The decrease in the (100) XRD diffraction peak in $\mathrm{Cu}(\mathrm{II})$-IIP provided evidence 
that grafting mainly occurs inside the mesopore channels [30]. The result was further demonstrated by TEM.

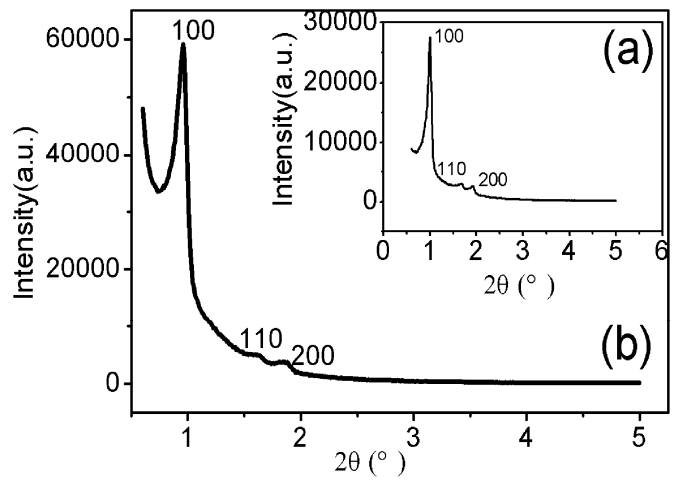

Fig. 4 XRD patterns of SBA-15 (a) and $\mathrm{Cu}(\mathrm{II})-\mathrm{IIP}(\mathrm{b})$

4) Morphology analysis

The morphology and microstructure of SBA-15 and $\mathrm{Cu}(\mathrm{II})$-IIP was analyzed by the SEM and TEM, respectively. The SEM images are presented in Fig. 5 (a) and (b). As can be seen, pure SBA-15 revealed short rod-like structures with relatively uniform size (Fig. 5 a). For the $\mathrm{Cu}$ (II)-IIP, the ordered morphology of SBA-15 was destroyed to a certain degree after a series of functionalization and the surface became rough since organic groups grafted on surface. Meanwhile, the TEM images were displayed in Fig. 5 (c) and (d). It can be clearly observed that channel-like structures running parallel to the longer direction, these channels displayed corresponded well to the typical structure of SBA-15. Compared with the two TEM images of SBA-15 and $\mathrm{Cu}$ (II)-IIP, we could conclude that the highly ordered mesoporous channels structure of the SBA15 was well maintained and the pore size was decreased after functionalization. The results were consistent with BET analysis.
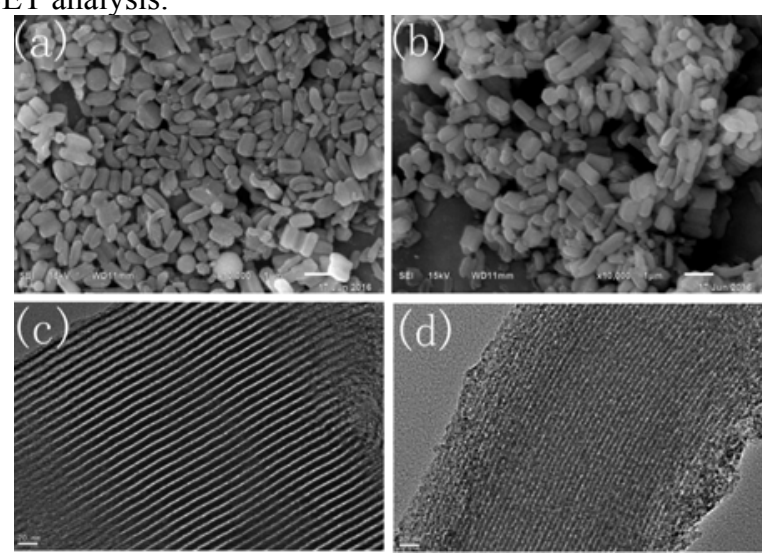

Fig.5 SEM images of SBA-15 (a) and Cu(II)-IIP (b), TEM images of SBA15 (c) and $\mathrm{Cu}(\mathrm{II})-\mathrm{IIP}(\mathrm{d})$

5) BET analysis

The nitrogen adsorption-desorption isotherms of SBA15 and $\mathrm{Cu}(\mathrm{I})$-IIP are shown in Fig. 6. All samples exhibited typical type IV isotherms with clear hysteresis loops of $\mathrm{H} 1$ type associated with capillary condensation at $P / P_{0}$ from 0.6 to 0.8. Despite the decrease in the adsorbed amount of $\mathrm{N}_{2}$ after polymerization in the surface of SBA-15, the shape of the hysteresis loops of $\mathrm{Cu}$ (II)-IIP remained the same. This also further indicated that the ordered hexagonal structure of SBA-15 was well preserved after modification.

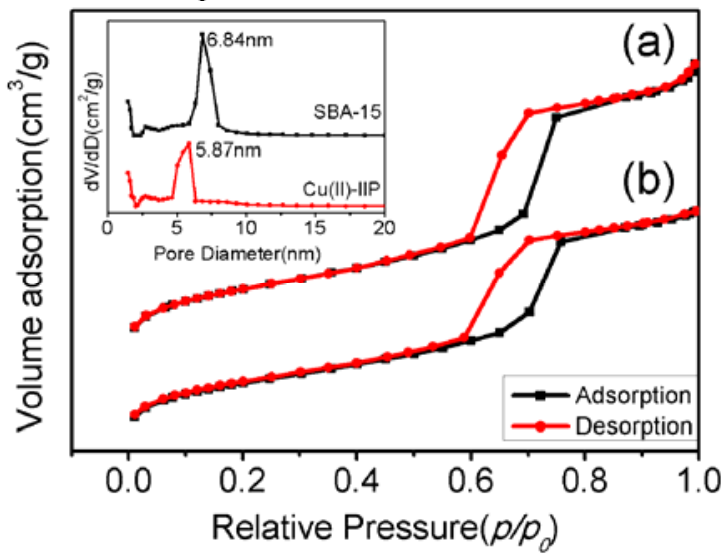

Fig.6. $\mathrm{N}_{2}$ adsorption-desorption isotherms and pore size distribution (inset) of SBA-15 (a) and Cu(II)-IIP (b). The pore size distribution was calculated by the BJH method.

Table 1 summarizes the physical parameters of SBA-15 and $\mathrm{Cu}(\mathrm{II})$-IIP that calculated from $\mathrm{N}_{2}$ adsorptiondesorption isotherms. $\mathrm{Cu}$ (II)-IIP shows a narrow pore size distribution centered at $5.87 \mathrm{~nm}$, BET surface area was $375.22 \mathrm{~m}^{2} \cdot \mathrm{g}^{-1}$ and its pore volume was $0.57 \mathrm{~cm}^{3} \cdot \mathrm{g}^{-1}$, which showed a larger relative diminution, in comparison to its native SBA-15 counterpart $\left(6.84 \mathrm{~nm}, 520.59 \mathrm{~m}^{2} \cdot \mathrm{g}^{-1}\right.$ and $0.75 \mathrm{~cm}^{3} \cdot \mathrm{g}^{-1}$ for SBA-15). These changes were attributed to the incorporation of organic groups into the mesoporous framework.

TABLE I. PHYSICAL PARAMETERS OF SBA-15 AND Cu(II)-IIP MEASURED BY NITROGEN ADSORPTION-DESORPTION ISOTHERMS

\begin{tabular}{cccc}
\hline Samples & $\begin{array}{c}\text { BET surfaces } \\
\text { area }\left(\mathrm{m}^{2} \cdot \mathrm{g}^{-1}\right)\end{array}$ & $\begin{array}{c}\text { Pore size } \\
(\mathrm{nm})\end{array}$ & $\begin{array}{c}\text { Pore volume } \\
\left(\mathrm{cm}^{3} \cdot \mathrm{g}^{-1}\right)\end{array}$ \\
\hline SBA-15 & 520.59 & 6.84 & 0.75 \\
$\mathrm{Cu}(\mathrm{II})-\mathrm{IIP}$ & 375.22 & 5.87 & 0.57
\end{tabular}

\section{6) TG analysis}

TG curves were employed to perform the thermal stability of $\mathrm{Cu}$ (II)-IIP. As can be seen in Fig. 7, all of the samples displayed a slight weight loss at temperatures from $40{ }^{\circ} \mathrm{C}$ to $200{ }^{\circ} \mathrm{C}$, which was mainly due to the loss of absorbed water. As for $\mathrm{Cu}$ (II)-IIP, it can be obviously seen that the weight loss increased rapidly in the temperature ranging from $300{ }^{\circ} \mathrm{C}$ to $900{ }^{\circ} \mathrm{C}$ because of the thermal decomposition of the polymer (approximately $13.34 \%$ ). The results also can demonstrated that the polymer was successfully grafted onto the surface of SBA-15. 


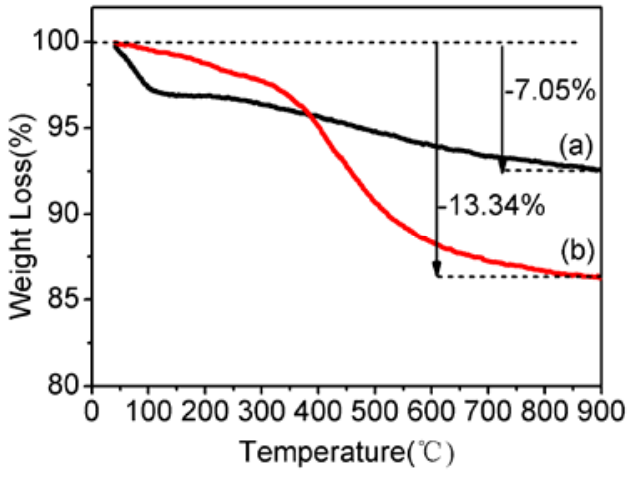

Fig. 7 TG curves of SBA-15 (a) and Cu(II)-IIP (b)

\section{Adsorption Experiments}

\section{1) Effect of $p H$}

$\mathrm{pH}$ is one of the most effective parameter for adsorption of metals on $\mathrm{Cu}$ (II)-IIP. The effect of $\mathrm{pH}$ values on $\mathrm{Cu}$ (II) ions adsorption was investigated at the range of $3-8$, which is depicted in Fig. 8. The adsorption capacity of $\mathrm{Cu}(\mathrm{II})$ increased with an increasing in $\mathrm{pH}$ from 3 to 7 , and then decreased slowly in $\mathrm{pH}$ from 7 to 8 and the maximum adsorption occurred around $\mathrm{pH}$ 7. It is explained that an excess of hydrogen ions have compete effectively with $\mathrm{Cu}$ (II) for bonding sites at acidic conditions, when the $\mathrm{pH}$ value was over 7 , the hydrolyzation of copper ions maybe occurred, resulting in low adsorption capacity of $\mathrm{Cu}$ (II)-IIP. Therefore, 7 was selected to be the optimum $\mathrm{pH}$ for further work.

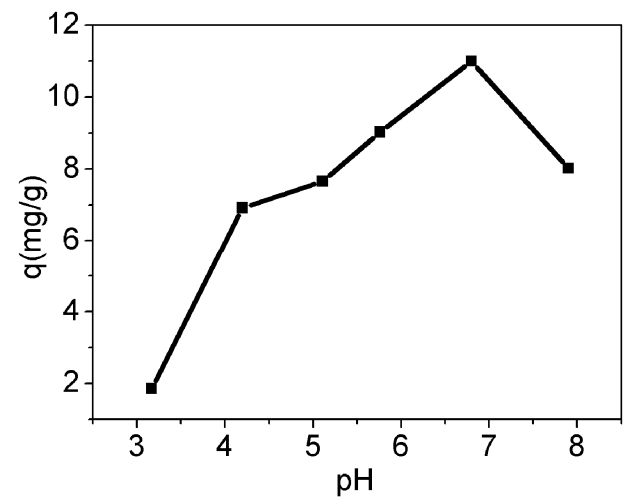

Fig. 8 Effect of $\mathrm{pH}$ on adsorption of $\mathrm{Cu}$ (II) onto $\mathrm{Cu}(\mathrm{II})$-IIP

\section{2) Adsorption kinetics}

The effect of contact time on adsorption of $\mathrm{Cu}(\mathrm{II})$ ions onto $\mathrm{Cu}$ (II)-IIP was shown in Fig. 9. The amount of $\mathrm{Cu}$ (II) ion adsorbed increases with time in the initial stage (0-40 min range), and then reach an equilibrium value in approximately $60 \mathrm{~min}$. A further increase in contact time had a negligible effect on the amount of ion adsorption. According to these results, the equilibrium time was fixed at $1 \mathrm{~h}$ for the subsequent adsorption experiments to ensure that equilibrium was achieved.

The applicability of different kinetics models to the adsorption behavior was studied to make a better understanding of the adsorption mechanism. In this study, The equations of pseudo-first-order and pseudo-secondorder shown as Eqs. (6) to (7) were employed to interpret the experimental data.

$$
\begin{gathered}
\ln \left(q_{e}-q_{t}\right)=\ln q_{e}-k_{1} t \\
\frac{t}{q_{t}}=\frac{1}{k_{2} q_{e}^{2}}+\frac{1}{q_{e}} t
\end{gathered}
$$

where $k_{1}\left(\mathrm{~min}^{-1}\right)$ and $k_{2}\left(\mathrm{~g} \cdot \mathrm{mg}^{-1} \cdot \mathrm{min}^{-1}\right)$ are the rate constants of pseudo-first-order and pseudo-second-order model.

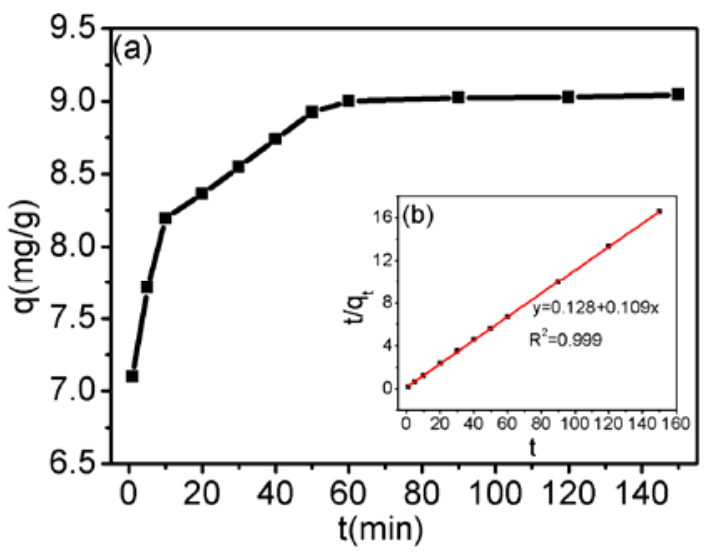

Fig.9 Effect of time on the adsorption of $\mathrm{Cu}$ (II) onto $\mathrm{Cu}(\mathrm{II})$-IIP (a)and fitting data by pseudo-second-order model (inset) (b)

The rate constants of adsorption and linear regression correlation coefficients for $\mathrm{Cu}$ (II)-IIP were presented in Table 2 and fitted data by pseudo-second-order model displayed in Fig.9 (inset), as can be clearly seen in the table, pseudo-second-order kinetic model well fit the adsorption of $\mathrm{Cu}$ (II) onto $\mathrm{Cu}$ (II)-IIP. Therefore, it is assumed that chemical process was the rate-limiting step in the adsorption process.

TABLE II. KINETIC PARAMETERS FOR Cu(II) ADSORPTION ON $\mathrm{Cu}$ (II)-IIP

\begin{tabular}{llllll}
\hline \multicolumn{2}{l}{ Pseudo-first-order kinetics } & \multicolumn{4}{l}{ Pseudo-second-order kinetics } \\
\hline$k_{1}\left(\mathrm{~min}^{-1}\right)$ & $q_{e q}\left(\mathrm{mg} \cdot \mathrm{g}^{-1}\right)$ & $\mathrm{R}^{2}$ & $k_{2}\left(\mathrm{~g} \cdot \mathrm{mg}^{-1} \cdot \mathrm{min}^{-1}\right)$ & $q_{e q}\left(\mathrm{mg} \cdot \mathrm{g}^{-1}\right)$ & $\mathrm{R}^{2}$ \\
0.0565 & 1.85 & 0.931 & 0.093 & 9.17 & 0.999 \\
\hline
\end{tabular}

\section{3) Adsorption isotherm}

The effect of initial ion concentration on $\mathrm{Cu}(\mathrm{II})$-IIP and NIP was investigated at the rang from 10 to $800 \mathrm{mg} \cdot \mathrm{L}^{-1}$. As can be seen from Fig.10. The adsorption capacity of $\mathrm{Cu}(\mathrm{II})-$ IIP for $\mathrm{Cu}$ (II) increased with increasing initial $\mathrm{Cu}$ (II) concentration in the aqueous solution. Compared with NIP, $\mathrm{Cu}$ (II)-IIP exhibited higher adsorption capacity at the corresponding concentration. The maximum adsorption capacity of $\mathrm{Cu}$ (II)-IIP was $25.03 \mathrm{mg} \cdot \mathrm{g}^{-1}$ higher than that of 
NIP at $25{ }^{\circ} \mathrm{C}$.The results proved that the prepared adsorbents had more adsorption sites for the $\mathrm{Cu}$ (II) by using imprinting technology.

The adsorption isotherms were used to assess the binding properties in the batch rebinding method, which was a key for understanding the adsorption mechanism. Therefore, the adsorption properties were evaluated by adsorption isotherms in the batch experiments, which is shown in Fig.10. The equations of Langmuir and Freundlich isotherms shown as Eqs. (8) to (9).

$$
\frac{C_{e}}{q_{e}}=\frac{1}{q_{m} k_{L}}+\frac{1}{q_{m}} C_{e}
$$

Where $k_{L}$ and $q_{m}$ are the Langmuir coefficients, referring to the adsorption equilibrium constant and the maximum adsorption capacity, respectively.

$$
\ln q_{e}=\ln K_{F}+\frac{1}{n} \ln C_{e}
$$

where $K_{F}$ is an indicative constant for the adsorption capacity and $1 / n$ is an empirical parameter.

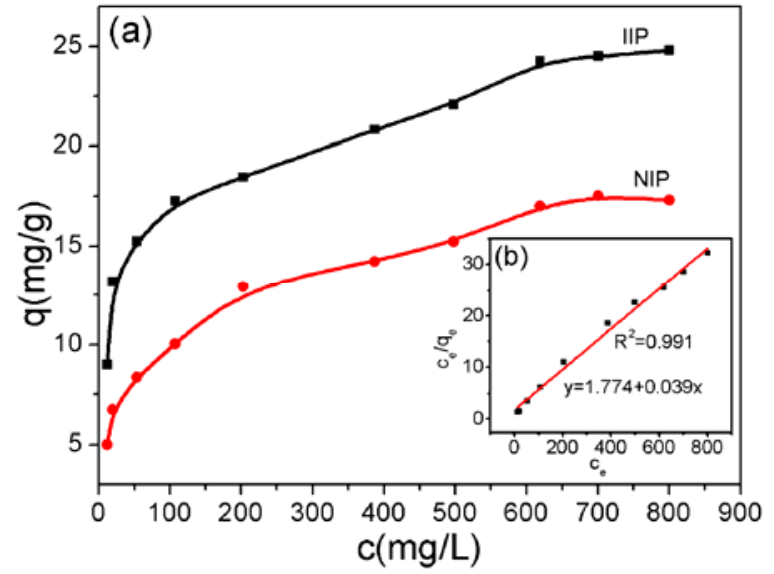

Fig. 10 Adsorption isotherms for adsorption of $\mathrm{Cu}$ (II) onto $\mathrm{Cu}(\mathrm{II})$-IIP and NIP (a) and fitting data by Langmuir isotherms (b)

The isotherm parameters obtained from linear analysis of the two isotherm models were also presented in Table 3 and fitting data by Langmuir isotherms displayed in Fig.10 (inset). Data showed that the adsorption of $\mathrm{Cu}(\mathrm{II})$ on $\mathrm{Cu}(\mathrm{II})$ IIP was well fitted to the Langmuir isotherm model.

TABLE III. THERMODYNAMIC PARAMETERS FOR ADSORPTION OF Cu(II) ONTO Cu(II)-IIP

\begin{tabular}{ccccccc}
\hline Sorbent & \multicolumn{3}{c}{ Langmuir model } & \multicolumn{3}{c}{ Freundlich model } \\
\cline { 2 - 7 } & $\begin{array}{c}q_{m} \\
\left(\mathrm{mg} \cdot \mathrm{g}^{-1}\right)\end{array}$ & $\begin{array}{c}k_{L} \\
\left(\mathrm{~mL} \cdot \mathrm{mg}^{-1}\right)\end{array}$ & $\mathrm{R}^{2}$ & $1 / n$ & $\begin{array}{c}K_{F} \\
\left(\mathrm{mg} \cdot \mathrm{g}^{-1}\right)\end{array}$ & $\mathrm{R}^{2}$ \\
\hline $\mathrm{Cu}(\mathrm{II})-\mathrm{IIP}$ & 25.64 & 0.022 & 0.991 & 0.207 & 6.283 & 0.942 \\
\hline
\end{tabular}

4) Selectivity study

Competitive adsorption of the same charge or similar ionic radius ions from binary mixtures such as $\mathrm{Cu}(\mathrm{II}) / \mathrm{Cd}(\mathrm{II})$,
$\mathrm{Cu}(\mathrm{II}) / \mathrm{Fe}(\mathrm{II}), \mathrm{Cu}(\mathrm{II}) / \mathrm{Co}(\mathrm{II}), \mathrm{Cu}(\mathrm{II}) / \mathrm{Pb}(\mathrm{II})$ were investigated by using $\mathrm{Cu}$ (II)-IIP and NIP, respectively. As can be seen in Table 4, the selectivity coefficient for $\mathrm{Cu}(\mathrm{II}) / \mathrm{Cd}(\mathrm{II})$, $\mathrm{Cu}(\mathrm{II}) / \mathrm{Fe}$ (II), $\mathrm{Cu}$ (II) $/ \mathrm{Co}(\mathrm{II}), \mathrm{Cu}(\mathrm{II}) / \mathrm{Pb}$ (II) were $3.56,2.32$, $11.75,4.73$, respectively. $\mathrm{Cu}(\mathrm{II})$-IIP exhibited an effective adsorption selectivity for $\mathrm{Cu}$ (II) in presence of competitive metal ions.

TABLE IV. DISTRIBUTION COEFFICIENT AND SELECTIVITY COEFFICIENT DATE OF Cu(II)-IIP AND NIP SORBENT

\begin{tabular}{cccccccc}
\hline $\begin{array}{c}\text { Metal } \\
\text { ions }\end{array}$ & \multicolumn{3}{c}{$\mathrm{Cu}(\mathrm{II})-\mathrm{IIP}$} & \multicolumn{3}{c}{$\mathrm{NIP}$} \\
\cline { 2 - 8 } & $\begin{array}{c}q \\
\left(\mathrm{mg} \cdot \mathrm{g}^{-1}\right)\end{array}$ & $\begin{array}{c}K_{d} \\
\left(\mathrm{~L} \cdot \mathrm{g}^{-1}\right)\end{array}$ & $k_{\mathrm{IIP}}$ & $\begin{array}{c}q \\
\left(\mathrm{mg} \cdot \mathrm{g}^{-1}\right)\end{array}$ & $\begin{array}{c}K_{d} \\
\left(\mathrm{~L} \cdot \mathrm{g}^{-1}\right)\end{array}$ & $k_{\mathrm{NIP}}$ & $k^{\prime}$ \\
\hline $\mathrm{Cu}(\mathrm{II})$ & 13.59 & 108.80 & 3.56 & 13.71 & 109.27 & 3.23 & 1.10 \\
$\mathrm{Cd}(\mathrm{II})$ & 3.80 & 30.54 & & 4.19 & 33.87 & & \\
$\mathrm{Cu}(\mathrm{II})$ & 13.94 & 105.02 & 2.32 & 13.09 & 99.79 & 1.81 & 1.28 \\
$\mathrm{Fe}(\mathrm{II})$ & 6.52 & 45.30 & & 7.80 & 55.07 & & \\
$\mathrm{Cu}(\mathrm{II})$ & 11.91 & 86.99 & 11.75 & 13.90 & 104.96 & 8.79 & 1.34 \\
$\mathrm{Co}(\mathrm{II})$ & 1.13 & 7.40 & & 1.80 & 11.94 & & \\
$\mathrm{Cu}(\mathrm{II})$ & 15.50 & 123.02 & 4.73 & 13.33 & 104.21 & 3.82 & 1.24 \\
$\mathrm{~Pb}(\mathrm{II})$ & 4.13 & 26.06 & & 4.30 & 27.28 & & \\
\hline
\end{tabular}

\section{5) Regeneration studies}

In practical application, the potentiality to be reused is considered as an important factor to assess the value of an absorbent. The results of the regeneration studies were shown in Fig. 11, there was no significant decrease in adsorption capacity after a test of up to five adsorptiondesorption cycles, demonstrating that the ion polymer is stable and reusable.

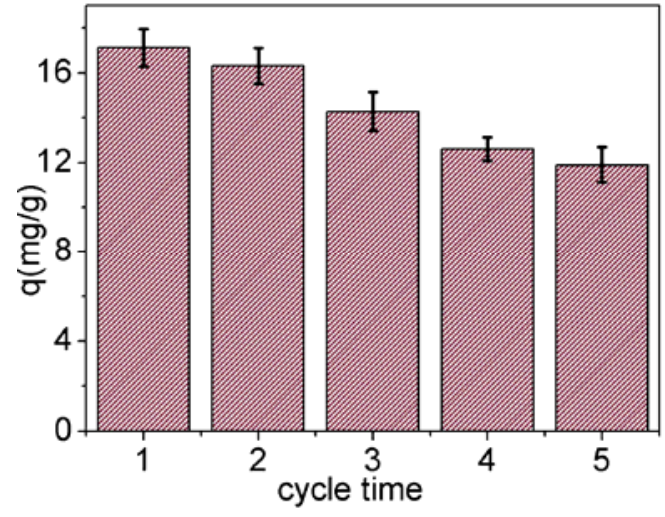

Fig. 11 Adsorption-desorption cycles of $\mathrm{Cu}(\mathrm{II})$-IIP

\section{CONCLUSIONS}

In this work, a new $\mathrm{Cu}$ (II) ion-imprinted polymer based on mesoporous SBA-15 functionalized with MPS was successfully synthesized by surface imprinting technique for selective removal of $\mathrm{Cu}$ (II) from aqueous solution. The imprinted polymer was characterized by FT-IR, EDS, XRD, TGA, SEM, TEM and $\mathrm{N}_{2}$ adsorption-desorption. The adsorption capacity for $\mathrm{Cu}$ (II)-IIP was higher than that of NIP under the same conditions. Adsorption isotherm experiments indicated that the Langmuir model was well fitted isotherm model. The kinetics of adsorption followed 
the pseudo-second-order model. Competitive adsorption studies illustrated that $\mathrm{Cu}$ (II)-IIP offered the advantages of selectivity toward $\mathrm{Cu}(\mathrm{II})$ in the presence of other metal ions. The prepared $\mathrm{Cu}$ (II)-IIP can be used more than five times without an obvious decrease in adsorption capacity, demonstrating that the $\mathrm{Cu}$ (II)-IIP supported on SBA-15 is stable and reusable.

\section{ACKNOWLEDGEMENTS}

The authors thank the support of the National Natural Science Foundation of China (No. 21266027 and No. U1507122)

\section{REFERENCES}

[1] Pereira FAR, Sousa KS, Cavalcanti GRS, et al. (2013) Chitosanmontmorillonite biocomposite as an adsorbent for copper (II) cations from aqueous solutions. Int. J.Biol. Macromol., 64:471-478.

[2] Debelius B, Forja J M, DelValls TA, et al. (2009) Toxicity of copper in natural marine picoplankton populations. Ecotoxicology, 18(8):1095-1103.

[3] Brown PA, Gill SA, Allen SJ (2000) Metal removal from wastewater using peat. Water Res. 34(16):3907-3916.

[4] He JS, Paul Chen J (2014) A comprehensive review on biosorption of heavy metals by algal biomass: Materials, performances, chemistry, and modeling simulation tools. Bioresour. Technol., 160:67-78.

[5] Stafiej A, Pyrzynska K (2007) Adsorption of heavy metal ions with carbon nanotubes, Sep. Purif. Technol., 58(1):49-52.

[6] Mauchauffée S, Meux E (2007) Use of sodium decanoate for selective precipitation of metals contained in industrial wastewater.Chemosphere 69(5):763-768

[7] Verma VK, Tewari S, Rai JPN (2008) Ion exchange during heavy metal bio-sorptionfrom aqueous solution by dried biomass of macrophytes. Bioresour. Technol., 99(6):1932-1938.

[8] Kurniawan TA, Chan GYS, Lo WH, et al. (2006) Comparisons of low-cost adsorbents for treating wastewaters laden with heavy metals. Sci. Total Environ. 366(2-3):409-426.

[9] Chethan PD, Vishalakshi B (2013) Synthesis of ethylenediamine modified chitosan and evaluation for removal of divalent metal ions Carbohydr. Polym., 97(2):530-536

[10] Alejandro GA, Virginia HM, Adrian BP (2011) Improving the adsorption of heavy metals from water using commercial carbons modified with egg shell wastes. Industrial and Engineering Chemistry Research,50(15):9354-9362.

[11] Yu JF, Wang YH, Fazle SH, et al. (2013) In situ synthesis of low silica $\mathrm{X}$ zeolite on ceramic honeycombs for adsorption of heavy metals. Journal of Porous Materials, 20(6):1525-1529.

[12] Ali S, Teruo HS, Tamao H, et al. (2011) Evaluating the adsorptive capacity of montmorillonitic and calcareous clays on the removal of several heavy metals in aqueous systems.Chemical Engineering Journal, 172(1):37-46

[13] Kumar KY, Muralidhara HB, Nayaka YA, et al. (2013) Low-cost synthesis of metal oxide nanoparticles and their application in adsorption of commercial dye and heavy metal ion in aqueous solution. Powder Technology, 246:125-136.

[14] Lu YK, Yan XP (2004) An imprinted organic-inorganic hybrid sorbent for selective separation of cadmium from aqueous solution. Anal. Chem., 76(2):453-457.

[15] Xiang GQ, Wen SP, Jiang XM, et al. (2011) Determination of trace copper(II) in food samples by flame atomic absorption spectrometry after cloud point extraction. Iran.J.Chem.Chem.Eng. 30(3):101-107.

[16] Mendil D, Karatas M, Tuzen M (2015) Separation and preconcentration of $\mathrm{Cu}(\mathrm{II}), \mathrm{Pb}(\mathrm{II}), \mathrm{Zn}(\mathrm{II}), \mathrm{Fe}(\mathrm{III})$ and $\mathrm{Cr}(\mathrm{III})$ ions with coprecipitation method without carrier element and their determination in food and water samples. Food Chem. 177, 320-324.

[17] Nafiseh K, Farzaneh S (2016) A new magnetic ion-imprinted polymer as a highly selective sorbent for determination of cobalt in biological and environmental samples. Talanta, 146:244-252.

[18] Chen LG, Xu SF, Li JH (2011) Recent advances in molecular imprinting technology: current status, challenges and highlighted applications. Chem Soc Rev, 40(5):2922-2942.

[19] Fu JQ, Chen LG, Lia JH (2015) Current status and challenges of ion imprinting.J. Mater. Chem. A, 3:13598-13627.

[20] Tsoi YK, Ho YM, Leung KSY (2012) Selective recognition of arsenic by tailoring ion-imprinted polymer for ICP-MS quantification. Talanta, 89:162-168.

[21] Luo XB, Huang YN, Deng F (2012) A magnetic copper(II)-imprinted polymer for the selective enrichment of trace copper(II) ions in environmental water. Microchim Acta, 179(3):283-289.

[22] Ashkenani H, Ali Taher M (2012) Selective voltammetric determination of $\mathrm{Cu}(\mathrm{II})$ based on multiwalled carbon nanotube and nano-porous $\mathrm{Cu}$-ion imprinted polymer. Journal of Electroanalytical Chemical, 683:80-87.

[23] Guo JJ, Su QD, Gan WE (2009) On-line Selective Solid-Phase Extraction of Copper with a Surface Ion Imprinted Silica Gel Sorbent. Journal of the Chinese Chemical Society, 56(4):763-770.

[24] Magner E (2013) Immobilisation of enzymes on mesoporous silicate materials. Chem.Soc. Rev. 42(15):6213-6222.

[25] Li JN, Qi T, Wang LN, et al. (2007) Synthesis and characterization of imidazole functionalized SBA-15 as an adsorbent of hexavalent chromium, Mater. Lett. 61(14-15):3197-3200.

[26] Meng XG , Liu Y, Meng MJ, et al. (2015) Synthesis of novel ionimprinted polymers by two different RAFT polymerization strategies for the removal of $\mathrm{Cs}(\mathrm{I})$ from aqueous solutions, RSC, Adv.,5(17): 12517-12529.

[27] Liu Y, Qiu J, Liu ZC, et al. (2016) Tailor-made ion-imprinted polymer based on functionalized graphene oxide for the preconcentration and determination of trace copper in food samples. J. Sep. Sci. 39:1371-1378.

[28] Zhao DY, Feng JL, Huo QS, et al. (1998) Stucky, Triblock copolymer syntheses of mesoporous silica with periodic 50 to 300 angstrom pores. Science, 279(5350):548-552.

[29] Dai S, Burleigh MC, Shin YS, et al. (1999) Imprint coating: A novel synthesis of selective functionalized ordered mesoporous sorbents. Angew. Chem. Int. Ed. Engl., 38(9):1235-1239.

[30] Liu Y, Liu ZC, Gao J, et al. (2011) Selective adsorption behavior of $\mathrm{Pb}(\mathrm{II})$ by mesoporous silica SBA-15-supported $\mathrm{Pb}(\mathrm{II})$-imprinted polymer based on surface molecularly imprinting technique. Journal of Hazardous Materials 186 (1):197-205. 